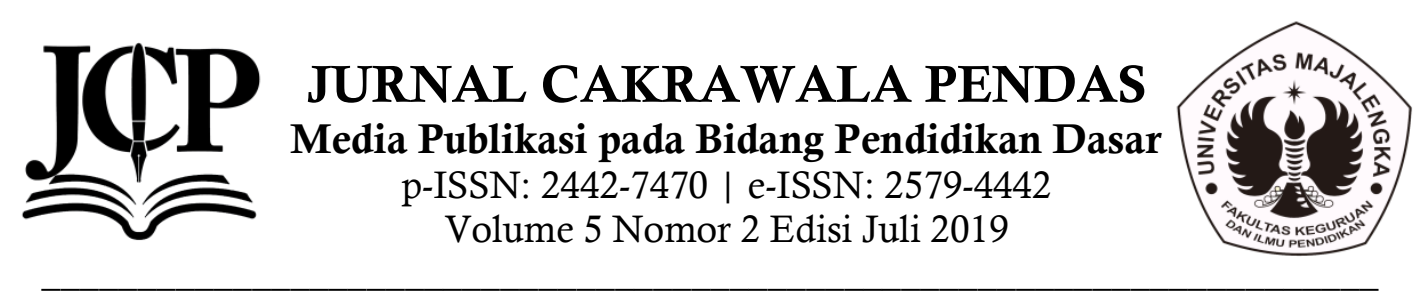

\title{
EFEKTIVITAS TERAPI APPLIED BEHAVIOR ANALYSIS (ABA) TERHADAP PERKEMBANGAN BAHASA ANAK BERKEBUTUHAN KHUSUS AUTISME
}

\author{
Mareyke Jessy ${ }^{1}$, Noviana Diswantika ${ }^{2}$ \\ ${ }^{1,2}$ Jurusan Bimbingan dan Konseling, STKIP PGRI Bandar Lampung \\ Email: ${ }^{1}$ farraakuan@gmail.com
}

\begin{abstract}
Abstrak
Anak dengan spektrum autis memiliki perkembangan yang cukup berat. Namun mereka memiliki hak yang sama layaknya anak yang normal lainnya. Perkembangan anak autis tidak sma dengan anak lainnya, mereka sering membentuk pola tertentu dan membutuhkan konsistensi yang tinggi. Anak autis membutuhkan dukungan dari berbagai pihak dalam mengoptimalkan kemampuannya. Penelitian ini bertujuan untuk mendeskripsikan efektivitas terapi ABA (Apllied Behavior Therapy) untuk meningkatkan bahasa anak autis, dan perkembangan bahasa anak autis setelah memperoleh terapy ABA. Sebelum metode ABA diterapkan, kemampuan kemampuan rata-rata anak untuk berbicara dengan satu jenis kosakata membutuhkan beberapa kali latihan dengan hasil yang kurang baik, namun setelah diberikan tindakan, maka kemampuan bahasa rata-rata anak autis mengalami peningkatan.
\end{abstract}

Kata kunci : ABA (Applied Behavior Therapy), Bahasa, Autisme

\begin{abstract}
Children with autism spectrum have a fairly heavy development. But they have the same rights as other normal children. The development of autistic children is not high school with other children, they often form certain patterns and require high consistency. Autistic children need support from various parties in optimizing their abilities. This study aims to describe the effectiveness of ABA (Apllied Behavior Therapy) therapy to improve the language of autistic children, and the language development of autistic children after obtaining ABA therapy. Before the ABA method is applied, the ability of the average ability of children to speak with one type of vocabulary requires several exercises with poor results, but after being given action, the average language ability of an autistic child increases.
\end{abstract}

Keywords: ABA (Applied Behavior Therapy), Language, Autism 


\section{Pendahuluan}

Anak merupakan harta yang paling berharga bagi setiap orangtua, yang harus dijaga, disayangi, dan diberi perhatian yang khusus terutama jika anak masih berada pada masa tumbuh kembang anak, yaitu antar usia lahir sampai 8 tahun. Di masa inilah anak berada pada fase keemasan atau yang sering kita sebut dengan golden age, karena di usia ini $80 \%$ otak anak berkembang dengan baik. Seperti halnya yang dikatakan oleh Hurlock (dalam Artanti tahun berapa) bahwa perkembangan anak pada usia awal mempengaruhi perkembangan anak selanjutnya.

Tumbuh kembang anak dapat dipengaruhi oleh dua faktor utama, yakni faktor genetik dan faktor lingkungan (Wong, dalam Rahmawati, 2008). Faktor lingkungan secara garis besar dibagi menjadi faktor lingkungan prenatal dan faktor lingkungan postnatal. Faktor lingkungan prenatal yang berpengaruh terhadap tumbuh kembang anak yakni gizi ibu pada saat hamil. Gizi ibu yang kurang dapat menghambat pertumbuhan otak janin (Soetjiningsih, 2002). Ada juga anak yang memang memiliki permasalahan dalam tumbuh kembang karena anak tersebut mengalami gangguan fisik. Salah satu gangguan perkembangan yang serng dikeluhkan oleh para orangtua serta kerap ditemui di sekitar kita ialah autisme. Autisme merupakan suatu kumpulan sindrom yang mengganggu saraf. Kondisi ini dapat mengganggu perkembangan anak, diagnosanya diketahui dari gejala-gejala yang tampak dan ditunjukan dengan adanya penyimpangan perkembangan (Prasetyono, 2008).

Kata autis berasal dari bahasa Yunani "autos" yang berarti sendiri. Autisme adalah gangguan spektrum. Ini berarti orang-orang yang menyandang autis tidak hanya memiliki gejala-gejala yang berbeda, tetapi intensitasnya juga beragam (Bonnice, 2009). Berdasarkan penelitian yang dilakukan oleh Barke EJ, BrandeisD, dkk 2013 (dalam Shah-mansouri, 2017) autisme diklasifikasikan dalam kategori Pervasive Developmental Disorders (PDDs). Gangguan dalam kategori ini melibatkan sekelompok masalah dan gangguan yang mempengaruhi kehidupan anak-anak. PDD muncul pada awal masa kanak-kanak, dan gangguan dalam interaksi sosial adalah aspek utama dari semua gangguan dalam kategori ini. Aspek utama dan menonjol dalam autisme adalah "sejak masa kanak-kanak ia tidak mampu berinteraksi dengan orang-orang dengan cara yang normal". Menurut definisi autisme ditandai oleh gangguan yang dapat menghambat beberapa tahap perkembangan pada anak, termasuk interaksi sosial dan hubungan, keterampilan, dan adanya perilaku stereotip, minat atau kegiatan. Gejala-gejala lain dalam anak autis termasuk gangguan bicara dan bahasa (termasuk echolalia, keterlambatan bahasa, dan pembalikan kata ganti), suasana hati yang labil dan mempengaruhi respon yang salah terhadap rangsangan sensorik; semua aspek ini dimulai sebelum usia 3 tahun (Wong, Odom, Hume, Cox, Fettig, \& Kucharzyk, 2015).

Suatu layanan yang diberikan bagi anak autis harus disesuaikan dengan metode yang tepat sehingga dapat di terapkan secara langsung. Beberapa metode tersebut antara lain metode Lovaas atau Applied Behavior Analysis (ABA) dan metode Son-Rise. Jessica Kingley (Kingley, 2006) mengemukakan "Applied Behavior Analysis (ABA) adalah ilmu yang menerapkan prinsip-prinsip yang diperoleh secara eksperimental perilaku sosial untuk meningkatkan perilaku yang signifikan. ABA mengambil apa yang kita ketahui tentang perilaku dan menggunakannya untuk membawa perubahan positif (Applied). Perilaku yang didefinisikan dalam istilah diamati dan terukur untuk menilai perubahan dari waktu ke waktu (Behavior). Perilaku dianalisis dalam lingkungan untuk menentukan faktor apa yang mempengaruhi perilaku (analisis). Pada penerapan metode Lovaas atau Applied Behavior Analysis (ABA) ini anak diajarkan menjadi disiplin karena kurikulumnya dimodifikasi dari aktivitas sehari hari dan dilaksanakan secara konsisten. Metode Lovaas atau Applied Behavior Analysis (ABA) ini memiliki ciri terukur, terarah dan terstruktur sehingga memudahkan disetiap pemantauan dan perkembangannya. Fokus 
penanganannya terletak pada pemberian penguatan yang positif setiap kali anak merespon dengan benar dan sesuai dengan instruksi yang diberikan.

\section{Metode Penelitian}

Metode yang digunakan dalam penelitian ini yaitu metode kualitatif dengan model studi kasus. Pada kasus ini peneliti melakukan observasi terhadap anak berkebutuhan khusus, yaitu autis dengan mengukur tingkat perkembangan bahasa nya. Metode penelitian studi kasus adalah metode yang meneliti suatu kasus atau fenomena tertentu yang ada dalam masyarakat yang dilakukan secara mendalam untuk mempelajari latar belakang, keadaan, interaksi yang terjadi. Studi kasus dilakukan pada suatu kesatuan sistem yang bisa berupa suatu program, kegiatan, peristiwa, atau sekelompok individu yang ada pada keadaan atau kondisi tertentu. Studi kasus akan memahami , menelaah, dan kemudian menafsirkan makna yang didapat dari fenomena yang diteliti tersebut. Peristiwa dalam penelitian ini yaitu efektivitas terapi applied behavior analysis terhadap perkembangan bahasa anak berkebutuhan khusus autisme.

\section{Hasil Dan Pembahasan}

Anak penyandang autis mempunyai gangguan dalam bidang interaksi sosial, yaitu tidak tertarik untuk bermain bersama teman, lebih suka menyendiri, tidak ada atau sedikit kontak mata atau menghindar untuk beratapan, senang menarik tangan orang lain untuk melakukan apa yang diinginkan (Ayes, 1998). Adanya gangguan pada dalam interaksi sosial pada anak autis dapat mempengaruhi aspek dalam belajar dan perilaku (Handojo, 2009). Apabila kelainan ini berlanjut sampai dewasa, maka akan menimbulkan dampak yang fatal, misalnya tidak dapat meminta bantuan pada orang lain karna adanya keterbatasan dalam kemampuan interaksi sosial, tidak memiliki kesempatan berkarya atau memiliki pekerjaan, sehingga pada akhirnya tidak akan mampu untuk memnuhi kebutuhan hidup atau kesehatannya.
Bahasa adalah media yang sangat penting dengan suara yang sempurna. Kita dapat berbicara tanpa menulis, tetapi tidak dapat menulis tanpa berbicara (setidaknya untuk diri kita sendiri). Anak-anak normal memperoleh bahasa secara mudah dan dapat mengikuti pembelajaran bahasa. Namun, beberapa anak berkebutuhan khusus karena berbagai alasan mengalami kesulitan dalam memperoleh bahasa dan pembelajaran bahasa. Padahal bahasa adalah salah satu aspek terpenting bagi manusia untuk dapat mengekspresikan diri, bersosialisasi, memperoleh pengetahuan dalam pendidikan dan digunakan dalam komunikasi dengan lingkungan. Anak harus memiliki pengalaman berbicara yang cukup agar bahasa anak dapat berkembang lebih baik, dengan penguasaan bahasa yang lebih luas maka mutu percakapan anak akan meningkat pula.

Pemahaman yang jelas tentang anak berkebutuhan khusus autis merupakan dasar yang penting untuk dapat menyelenggarakan layanan bantuan yang tepat bagi mereka. Dengan kecerdasan yang dimiliki di bawah rata-rata anak normal, anak berkebutuhan khusus autis mengalami kesulitan dalam hal menyesuaikan diri dengan lingkungan dan kurang cakap dalam hal-hal yang abstrak. terdapat perbedaan yang besar antara anak autis yang satu dengan yang lainnya.

Metode ABA (Applied Behvior Analysis) dipilih sebagai teknik dalam mengembangkan bahasa anak berdasarkan pertimbangan bahwa :

1) Komunikasi dua arah yang aktif

2) Sosialaisasi ke dalam lingkungan yang umum

3) Menghilangkan atau meminimalkan perilaku yang tidak wajar

4) Mengajarkan perilaku yang akademik

5) Kemampuan bantu diri atau bina diri dan keterampilan lain

Hasil penelitian menunjukkan efektivitas metode ABA dapat diketahui melalui respon positif oleh terapis. Namun respon positif ini diperoleh setelah beberapa kali pertemuan yang tingkat pembelajarannya disesuaikan dengan kondisi anak. Berdasarkan rangsangan metode ABA yang diberika kepada anak autis didapatkan gambaran bahwa setiap 
rangsangan yang diberikan terapis ditanggapi oleh anak autis dan dinilai dalam bentuk penghargaan untuk kemajuan perolehan perkembangan bahasanya. Menurut Cahucad (1983) setiap anak membentuk bahasa berdasarkan kemungkinan kekuatan neuron motoriknya. Ia harus membentuk bahasa untuk dirinya sendiri. dengan belajar bicara maka anak akan belajar memiliki kesadaran berbahasa. Perkembangannya sedikit tetapi harus terus berkembang. Perkembangan bahasa dimulai dari usia 3 tahun dan secara bertahap akan menjadi sempurna ditahuntahun berikutnya.

Dalam penelitian terungkap bahwa pelaksanaan program terapi anak autis meliputi penentuan penggunaan metode, media jenis terapi dan tentunya pelaksanaan program tersebut. Ketika anak sudah mulai beradaptasi dengan lingkungan terapi, kemudian proses terapi dimulai sesuai dengan kebutuhan dasar anak. Terapi ini berupa terapi perilaku dan wicara. Terapi perilaku merupakan terapi yang bertujuan untuk menghilangkan atau meminimalkan perilaku yang tidak wajar pada penderita autisme. Penerapannya harus dilakukan dengan penuh kesabaran dan ketelatenan. Terapi perilaku dengan metode ABA ini lebih ditakankan pada pelatihan kontak mata, motorik kasar, mengikuti instruksi sederhana, mengetahui anggota tubuh, melihat gambar, mencocokan, serta untuk melatih kemampuan anak mengenai warna, bentuk, huruf, dan angka (Lembaga Terapan Autisme Indonesia, 2000). Terapi ini biasanya dimulai dengan hal yang sederhana dan paling dasar, yaitu melatih kontak mata, kemampuan dilanjutkan dengan kemampuan melatih kemampuan motorik kasar sederhana, misalnya mengangkat gelas atau cangkir. Anak dapat diberi bnatuan dengan menjaga nya dari arah belakang anak. Apabila anak telah mampu melakukannya dengan baik, maka tidak lupa ia akan diberikan imbalan kepada anak sebagai reinforcement. Pada terapi wicara, tidak diberikan secara langsung, namu saat pemberian instruksi ketika proses terapi berlangsung. Misalnya ketika terapis mempersilahkan anak-anak untuk masuk ke ruang terapi, terapis akan mengucapkan "silahkan masuk" secara jelas dan tegas, dan kemudian anak pun mengikuti instrusi tersebut. Dalam memberikan instruksi, kalimat pendek nan sederhana digunakan agar anak mudah untuk memahami maksudnya. Percakapan yang berlangsung dengan anak menyiratkan penguasaan motorik sensorik agar anak mampu mengenali suara yang sidengarnya, mampu mengendalikan semua reaksi yang memungkinkan pelafalan bunyi yang diinginkan. Oleh karena itu tidak mengherankan apabila kemajuan bahasa berkaitan dengan kemampuan motorik anak.

Namun dalam pelaksanan terapi ini ada beberapa hal yang menjadi hambatan, diantaranya anak yang hiperaktif, anak sulit untuk fokus, kesulitan bicara, dan perilaku anak yang tidak terarah. Penggunaan metode ABA yang efektif menunjuk pada pengertian memiliki pengaruh yang baik dalma membangun pemahaman melalui aksen-aksen visual. Dengan hal ini perkembangan bahasa anak akan meningkat.

\section{Kesimpulan}

Autisme merupakan spektrum sindroma kelainan neurologis yang tidak bisa disembuhkan. Dengan kelainan utamanya yaitu adanya gangguan pada trias komunikasi, imajinasi, dan interaksi sosial. Dengan menggunakan teknik ABA dan berbagai modifikasinya anak dengan gangguan autis bisa ditingkatnya kemampuannya untuk berkomunikasi dan berbahasa. Namun penanganan nya membutuhkan kesungguhan agar perkembangan yang diinginkan dapat meningkat. Kondisi yang ditampilkan tiap anak juga berbeda dari satu anak dengan anak lainnya, tentu hal ini akan berpengaruh pada hasil akhir yang didapatkan, tergantung pada kuantitas dan kualitas autisme anak, intensitas penanganan sejak dini, kemampuan anak dalam berkomunikasi serta konsistensi pola asuh anak dalam keluarga.

\section{Daftar Pustaka}

Artanti, P. Y. (2012). Studi Deskriptif Terapi Terhadap Penderita Autisme Pada Anak Usia Dini di Mutia 
Center Kecamatan Bojong Kabupaten Purbalingga. Indonesian Journal Of Early Childhood Education Studies , 44-48.

Bonnice, S. (2009). Anak yang Tersembunyi Pemuda Autis (Terjemahan Oleh Moses Aries Romawan dan Imam Setiadji). Sleman: KTSP.

Chaer, A. (2003). Psikolinguistik (Kajian Teoritik). Jakarta: PT Rineka Cipta.

Chauchard, P. (1983). Bahasa dan Pikiran. Translate by A. Widyamartaya. Yogyakarta: Saunders Company.

Danim, S., \& Khairil. (2010). Psikologi Pendidikan (Dalam Persepektif Baru). Bandung: Alfabeta.

(1994). Diagnostic and Statistical Manual of Mental Disorder. Washington DC: Anerican Psychiatri Association.

Dunlap, G., Carr, E. G., Horner, R. H., Zarcone, J. R., \& Schwartz, I. (2008). Positive Behavior Support and Applied Behavior Analysis : A Familian Alliance. Sage Publications, 682-698.

Handojo, Y. (2009). Autisme Pada Anak. Jakarta: PT Buana Ilmu Populer Kelompok Gramedia.

Hardiani, R. S., \& Rahmawati, S. (2012). Metode ABA (Applied Behavior Analysis) : Kemampuan Bersosialisasi Terhadap Kemampuan Interaksi Sosial Anak Autis. Jurnal Keperawatan Soedirman , 1-9.

Kentjono, D. (1990). Dasar-Dasar Linguistik Umum. Fakultas Sastra Universitas Indonesia.

Kingley, J. (2006). Applied Behavior Analysis. Jakarta: Gramedia.

Leaf, R., \& McEachin, j. (1999). A Work in Progress : Behavioural Management Strategis and Curriculum for Intensive Behavioural Treatment of Autism. new York: DRL Books.
Lovaas, O. (2003). Teaching Individuals with Developmental Delays : Basic Intervention Techniques. Texas: Pro-Ed.

Movahedzadeh, B., \& Shah-mansouri, M. J. (2017). Effectiveness of Applied Behavior Analysis In The Self-Help Skills and Stereotyped Behaviors of Children with Autism pectrum Disorder in Isfahan. Social Determinant of Health , 141-147.

Pamoedji, G. (2007). Seoutar Autisme. Jakarta: Gramedia.

Prasetyono. (2008). Serba-Serbi Anak Autis. Jogjakarta: DIVA Press.

Scariano, M., \& Grandin, T. (1986). Emergence : Labeled Autistic.

Soendari, R., \& Wismiati. (2010). Sentra Persiapan. Jakarta: Pustaka Al-Fallah.

Watson, J. (1914). Behavior : An Introduction to Comparative Psychology. new York: Henry Holt and Company.

Wong, C., Odom, S., Hume, K., Cox, A., Fettig, A., \& Kucharzyk, S. (2015). Evidence-Based Practices For Children, Youth and Young Adults with Autism Spectrum Disorder : A Comprehensif Review. J Autism Dev Disorder , 51-66.

Yuliantina, I. (2014). Peningkatan Kemampuan Bahasa Awal Melalui Alat Permainan Edukatif. Jurnal Pendidikan Anak Usia Dini , 111-118. 